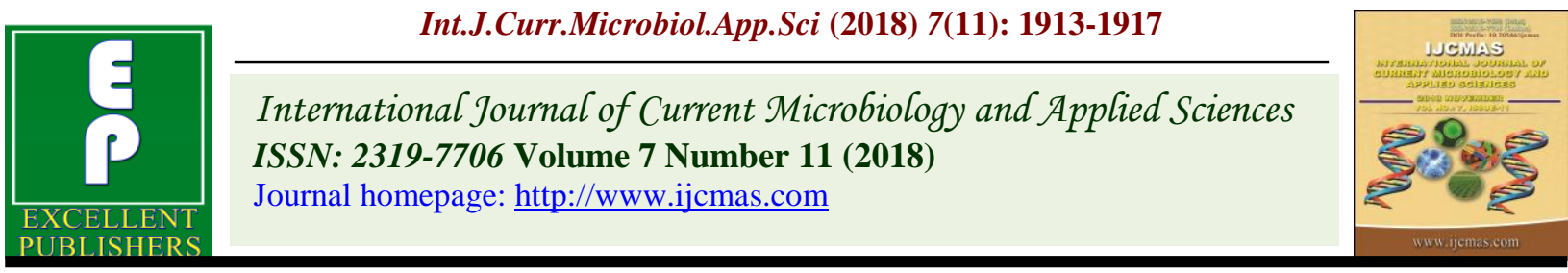

Original Research Article

https://doi.org/10.20546/ijcmas.2018.711.216

\title{
Relationship between the Weather Variables and Wheat Yield under Raipur Condition
}

\author{
Anil Kumar Thakur*, Shri J.L. Chaodhary, Deepak Kurre and Usha Durgam \\ Department of Agrometeorology, Indira Gandhi Krishi Vishwavidyalaya, \\ Raipur (C.G.) - 492012, India \\ *Corresponding author
}

\begin{abstract}
A B S T R A C T
Keywords

Wheat yield, Weather

variables, Correlation,

Regression, Phenological stage

Article Info

Accepted:

15 October 2018

Available Online:

10 November 2018

This study examines the effect of climatic factor e.g. Maximum Temperature, Minimum Temperature and sunshine variation on the yield of different stages of wheat in during Rabi season 2015-16 at research and instructional farm of IGKV Raipur (CG) India. The correlations of average wheat yield for 14 crop seasons (2001-02 to 2015-16) have been studies for kanchan variety. The year wise variation in grain yield may be considered more pronounced due to variation in weather variables and their inter-relationship effects rather than factors involved in raising crop for different phenological stages. Multiple Correlations analysis has used to estimate the relationship of climate variables on the wheat yield. The main effects of all the variables were observed to have statistically nonsignificant contribution towards changing crop yield. However, the interaction of relative humidity with other weather variables was estimated to have statistically significant contribution towards yield variability.
\end{abstract}

\section{Introduction}

Evidently climate change is being realized in every walk of our life. Palpable impact is seen on growth and development, water use and productivity of major crops including wheat. Recently much attention has been given to the effects of climate change on agricultural output, because of the relevance of agriculture to the world economy, and the sensitivity of crop yields to climate conditions. Climate change impacts on India can have far-reaching consequences, as well; India is the world's second largest producer of agricultural outputs, and any changes in production due to climate change could materially impact global agricultural imports and exports. Agriculture is the most vulnerable sector to climate change. Agriculture productivity is being affected by a number of factors of climatic change including rainfall pattern, temperature, relative humidity, evaporation, changes in sowing and harvesting dates, water availability, and evapo-transpiration 4 and land suitability. All these factors can change yield and agricultural productivity. The impact of climate change on agriculture is many folds including diminishing of agricultural output and shortening of growth period for crops.

Wheat (Triticum aestivum L) is the most widely cultivated food grain crop of the world. 
It is grown not only in temperate zones but also in tropical and subtropical zones. In India, wheat is the second important staple food crop, rice being the first (Agrawal and Sinha, 1993). It has wide adaptability and can tolerate severe cold also. The best quality wheat is produced with cool and moist weather during the vegetative phase followed by dry warm weather during reproductive phase (Draganka et al., 2004). It is a long day plant. Temperature ranging between $20^{\circ}$ to $25^{\circ} \mathrm{C}$ is ideal for seed sowing and germination. Whereas the optimum temperature for vegetative growth ranges from $16^{\circ}$ to $22^{\circ} \mathrm{C}$. During the grain development wheat requires a mean maximum temperature of about $25^{\circ} \mathrm{C}$ for at least 4-5 weeks. Wheat is grown well in those areas where annual rainfall ranges between $1200 \mathrm{~mm}$ to $1600 \mathrm{~mm}$. Winter wheat generally completes its life-cycle most rapidly when grown in low temperatures during the early stages of growth but high temperature is required during the later stages of growth (Bobade, 2010).

Seasonal temperature is an important climatic factor which has profound effects on the yield of rabi crops. Changes in seasonal temperature affect the grain yield, mainly through phonological development processes. Winter crops are especially vulnerable to high temperature during reproductive stages and differential response of temperature change (rise) to various crops has been noticed under different production environments (Kaur and Hundal, 2007). In Chhattisgarh on the effect of weather parameters particularly temperature during crop growing season at various phenophases of the crop.

\section{Materials and Methods}

Often several quantitative variables are measured on each member of a sample. If we consider a pair of such variables, it is frequently of interest to establish if there is a relationship between the two; i.e. to see if they are correlated (Anonymous 2014).

We can categorize the type of correlation by considering as one variable increases what happens to the other variable:

Positive correlation - the other variable also has a tendency to increase;

Negative correlation - the other variable has a tendency to decrease;

No correlation - the other variable does not tend to either increase or decrease.

SPSS software (Statistical Package for the Social Sciences) is used version SPSS 16.0 Copyright 2007 is a data analyzing software through which different types of data may be analyzed on statistical basis, like in MS-Excel. Yield is predicted through a model thus a correlation analysis needs to be described between yield and weather parameters using SPSS software (http://www.spss.com). In this study, yield prediction of wheat on meteorological basis was the main intention; therefore this model is utilized to find out the yield predictors. A decadal meteorological data of the last 15 years for Rabi season i.e. November to April (which has shown significant correlation with wheat yield) as input for the model. The yield data $(\mathrm{Kg} / \mathrm{ha})$ treated as dependant variable and the method employed is multiple linear regression (Kazmi et al., 2012).

\section{Results and Discussion}

\section{Correlation}

The correlations of average wheat yield for 14 crop seasons (2001-02 to 2015-16) have been studies for kanchan variety. The year wise variation in grain yield may be considered more pronounced due to variation in weather 
variables and their inter-relationship effects rather than factors involved in raising crop for different phenological stages. (Kumar et al., 2001) The linear correlation analysis (Table 1) shows that in CRI stage on wheat no weather variable was significantly correlated with grain yield though, maximum temperature, minimum temperature, rainfall and bright sunshine hours were positively correlated with grain yield. In tillering stage on wheat no weather variable was significantly correlated with yield however maximum temperature, rainfall and sunshine are having positive correlation while minimum temperature was negatively correlated though a negative and non-significant correlation coefficient is found.

In EMR stage on wheat cultivar all weather variables were negatively correlated though all relations and correlation coefficients are found to be non- significant. In $50 \%$ flowering stage maximum temperature and rainfall was significantly correlated with grain yield $(\mathrm{r}=$ $0.498),(\mathrm{r}=0.316)$ respectively at $\mathrm{LSD},(\mathrm{p}=$ $0.01),(p=0.05)$, while relationship with other variables were non-significant. In milk stage on wheat crop maximum temperature again was found to be have having significantly negative correlation with wheat yield $(\mathrm{r}=$ 0.368) at LSD, $(\mathrm{p}=0.05)$, while relationship with other variables were found not significant. In dough stage the rainfall and sunshine were have non-significant positive correlation and maximum and minimum temperature are found to be having nonsignificant negative correlation with wheat yield. In physiological maturity crop growth stage the weather variables maximum temperature, minimum temperature and rainfall were having non- significant negative correlation with wheat yield and sunshine found to have significant positive correlation. The results obtained from this analysis indicate that higher maximum temperature during $50 \%$ flowering and milking stage is going to cause a reduction in the grain yield of wheat crop. This may be due to effect on physiological mechanism and thermal stress condition which is affecting the metabolic activities in the plant. Meteorological parameters favorable rainfall is found to have the positive relation as this crop is requiring water requirement at critical stages of CRI, tillering, jointing, heading (50\% flowering) and hence rainfall as this stage might be helping meet its crop water requirements.

In case of four broad crop growth stages in Raipur condition, the linear correlation analysis (Table 2) show that the pre establishment stage on wheat crop, weather variables are having non- significant correlation with the grain yield though maximum temperature, minimum temperature, rainfall and sunshine weather variables are positively correlated. In vegetative phase on wheat crop no weather variable was having significantly correlation with grain yield though maximum temperature, rainfall and sunshine hours were positively correlated with grain yield and minimum temperature was negatively correlated. In crop reproductive phase maximum temperature was significantly correlated with grain yield $(\mathrm{r}=-0.434)$ at LSD (0.01), while relationship with other variables were not significant. In maturity phase on wheat crop all variables are having no significant correlation but maximum and minimum temperature are negatively and rainfall, sunshine hours positively correlated.

However it has been clear from the statistics that rainfall influenced the grain yield both positively and negatively. The highest significant effect of rainfall was observed during $50 \%$ flowering. Rainfall at crucial phases of CRI, tillering, emergence, 50\% flowering, milking and dough stages is helping to meet the crop water requirement which includes maintaining soil moisture status and evapotranspirational losses. 
Table.1 Relationship between weather variables and grain wheat yield for all phonological stages at Raipur

\begin{tabular}{|c|c|c|c|c|c|c|c|}
\hline $\begin{array}{c}\text { Weather } \\
\text { variables }\end{array}$ & \multicolumn{7}{|c|}{ Correlation coefficient (r) } \\
\hline MaxT & 0.13 & 0.118 & -0.123 & $-0.498^{* *}$ & $-0.368^{* *}$ & -0.148 & -0.009 \\
\hline MinT & 0.039 & -0.172 & -0.015 & -0.096 & -0.115 & -0.189 & -0.039 \\
\hline RF & 0.165 & 0.047 & -0.175 & $0.316^{*}$ & 0.236 & 0.119 & -0.125 \\
\hline SS & 0.165 & 0.032 & -0.099 & -0.099 & -0.143 & 0.221 & 0.162 \\
\hline
\end{tabular}

Table.2 Relationship between weather variables and grain wheat yield for Four phenophases at Raipur

\begin{tabular}{|c|c|c|c|c|}
\hline \multirow{2}{*}{$\begin{array}{l}\text { Weather } \\
\text { variables }\end{array}$} & \multicolumn{4}{|c|}{ Correlation coefficient $(r)$} \\
\hline & $\begin{array}{c}\text { Pre-establishment } \\
\text { phase }\end{array}$ & $\begin{array}{l}\text { Vegetative } \\
\text { phase }\end{array}$ & $\begin{array}{c}\text { Reproductive } \\
\text { phase }\end{array}$ & $\begin{array}{c}\text { Maturity } \\
\text { phase }\end{array}$ \\
\hline MaxT & 0.232 & 0.209 & $-0.434^{* *}$ & -0.102 \\
\hline MinT & 0.212 & -0.067 & -0.128 & -0.147 \\
\hline RF & 0.12 & 0.162 & 0.18 & 0.191 \\
\hline SS & 0.128 & 0.108 & -0.166 & 0.243 \\
\hline
\end{tabular}

At some stages like tillering and dough stages, the relationship with rainfall for Kanchan variety is found to be nonsignificant. The possible explanation for this is that the experiment is taken under assured irrigation and response with rainfall might become apparent only coinciding with soil moisture stress condition. It has been found that higher sunshine values at CRI, dough and physiological maturity stages will contribute for higher grain yield production while more values of sunshine during $50 \%$ flowering and milking stage can adversely affect normal functioning and lead to physiological stress thereby adversely affecting the grain yield. Overall it can be said that because of response of Kanchan variety to all the meteorological parameters, 50\% flowering and milking stage in wheat is found to be the most crucial stage. The influence of meteorological parameters will finally contribute to the grain yield. In this stage, maximum temperature, minimum temperature and sunshine are found to be negatively correlated while the rainfall has been found to be positively affecting the grain yield. Here, it is to mention here that meteorological factors are not affecting the metabolic activities and physiological mechanisms in their individual capacity but these are affecting the plant growth and development and final output in conjunction with one another.

Overall it can be said that because of response of Kanchan variety to all the meteorological parameters, milking stage in wheat is found to be the most crucial stage. The influence of meteorological parameters will finally contribute to the grain yield. In this stage, maximum temperature, minimum temperature and sunshine are found to be negatively correlated while the rainfall has been found to be positively affecting the grain yield.

In crop reproductive phase maximum temperature was significantly correlated with grain yield, while relationships with other variables were not significant. 


\section{References}

Agrawal, P.K. and Sinha, S.K. 1993. Effect of increase in carbon dioxide and temperature on wheat yield in India. Journal of Agrometeorology, 48: 811814.

Anonymous. 2014. Department of Agrometeorology College of Agriculture Indira Gandhi Krishi Vishwavidyalaya, Raipur (C.G.) 492012.

Bobade, P. 2010. Influence of weather parameters on growth and yield of wheat cultivars under different thermal environments. Thesis department of agrometeorology, IGKV Raipur p: 1-6.

Chmielewski, F.M., Potts, J.M. 1995. The relationship between crop yields from an experiment in southern England and long term climate variations. Agricultural and Forest-Meteorology, 73(1/2): 43-66.
Draganska, E., Kuchar, L., Szwejkowski, Z. 2004. Weather-crop model selection by Cross Validation test for winter wheat cultivated in North-Eastern Poland. Acta Scientiarum-PolonorumAgricultura, 3(1): 29-36.

Kaur, P. and Hundal, S.S. 2007. Effect of temperature rise on growth and yield of wheat: A simulation study. Journal of Research (PAU), 44(1): 6-8.

Kazmi, D.H. and Rasul, G. 2012. Agrometeorological wheat yield prediction in rainfed Potohar region of Pakistan. Agricultural Sciences, 3(2): 170-177.

Kumar, S., Mishra, H.S., Sharma, A.K. and Kumar, S. 2001. Effect of weather variables on the Yield of early, timely and late sown wheat in the Tarai Region. Journal Agriculture Physics, 1(1): 58-60.

\section{How to cite this article:}

Anil Kumar Thakur, Shri J.L. Chaodhary, Deepak Kurre and Usha Durgam. 2018. Relationship between the Weather Variables and Wheat Yield under Raipur Condition. Int.J.Curr.Microbiol.App.Sci. 7(11): 1913-1917. doi: https://doi.org/10.20546/ijcmas.2018.711.216 